\title{
Cystic Fibrosis Gene Mutations and Pancreatitis Risk: Relation to Epithelial Ion Transport and Trypsin Inhibitor Gene Mutations
}

\author{
PEADAR G. NOONE,* ZHAOQING ZHOU, ${ }^{\ddagger}$ LAWRENCE M. SILVERMAN, ${ }^{\ddagger}$ PAUL S. JOWELL, $\$$ \\ MICHAEL R. KNOWLES, * and JONATHAN A. COHN§ \\ Departments of *Medicine and ${ }^{\dagger}$ Pathology and Laboratory Medicine, University of North Carolina, Chapel Hill; and \$Department of Medicine, \\ Veterans Affairs and Duke University Medical Centers, Durham, North Carolina
}

\section{See editorial on page 1508.}

Background \& Aims: Nonalcoholic chronic pancreatitis is usually idiopathic and often associated with cystic fibrosis gene (CFTR) mutations. It is unknown whether pancreatitis risk correlates with having 1 or 2 CFTR mutations, abnormal epithelial ion transport, or mutations of other genes. Methods: We tested 39 patients with idiopathic chronic pancreatitis (mean age at diagnosis, 33 years) for common mutations of CFTR and of genes encoding a trypsin inhibitor (PSTI) and trypsinogen (PRSS1). To exclude hereditary pancreatitis, we initially relied on family history and subsequently tested for PRSS1 mutations. Twenty subjects were tested for rare CFTR mutations (DNA sequencing) and 11 were tested for extrapancreatic CFTR function (clinical and physiologic evaluation). Results: Mutations were identified in 24 of 39 subjects. Nine patients had cystic fibrosiscausing mutations, 8 of whom also had mild-variable mutations. Eight others had only mild-variable mutations. Nine subjects had the N34S PSTI mutation and 1 had hereditary pancreatitis (R122H, PRSS1). Pancreatitis risk was increased approximately 40 -fold by having 2 CFTR mutations $(P<0.0001), 20$-fold by having N34S $(P<0.0001)$, and 900 -fold by having both $(P<$ 0.0001 ). Subjects with 2 CFTR mutations had abnormal nasal epithelial ion transport and clinical findings suggesting residual CFTR function between that in cystic fibrosis and in carriers. By contrast, subjects with only PSTI mutations had normal CFTR function. Conclusions: CFTR-related pancreatitis risk correlates with having 2 CFTR mutations and reduced extrapancreatic CFTR function. The N34S PSTI mutation increased risk separately. Testing for pancreatitis-associated CFTR and PSTI genotypes may be useful in nonalcoholic pancreatitis.

$\mathrm{N}$ onalcoholic chronic pancreatitis commonly leads to recurrent abdominal pain, pancreatic insufficiency, and life-threatening complications. ${ }^{1}$ Even though nonalcoholic chronic pancreatitis is usually idiopathic and sporadic, ${ }^{2,3}$ recent studies have associated this condition with mutations in CFTR, the gene that causes cystic fibrosis (CF). ${ }^{4,5}$

It is unknown whether pancreatitis risk is mainly associated with having 1 or 2 CFTR mutations. This is important because $\mathrm{CF}$ carriers (with $1 \mathrm{CF}$-causing mutation) represent $3 \%-4 \%$ of the general population. Combining the data from several recent studies, $18 \%$ of individuals with idiopathic chronic pancreatitis had common CF-causing mutations, whereas only $2 \%$ were recognized as compound heterozygotes who had both a milder CFTR mutation and a CF-causing mutation. ${ }^{4-9}$

We suspected that these published studies underestimated the frequency of CFTR compound heterozygotes in pancreatitis because they did not comprehensively test for rare CFTR mutations. Thus, one goal of this study was to perform more detailed genetic testing to determine the prevalence of rare CFTR mutations in individuals who would have been classified as CF carriers based on routine genetic testing.

It is also unknown whether other genes modify the risk of CFTR-related pancreatitis. Mutations in the pancreatic secretory trypsin inhibitor gene (PSTI or SPINK1) have recently been associated with childhood pancreatitis. ${ }^{10,11}$ Because PSTI expression is acinar ${ }^{12}$ and CFTR is ductular, ${ }^{13}$ we anticipated that these genes might independently influence pancreatitis risk. If so, then testing for PSTI mutations might identify a subset of CF carriers in whom the risk of pancreatitis is especially high. ${ }^{12,14}$

To better define the link between CFTR mutations and pancreatitis risk, we performed detailed testing on a series of patients with idiopathic chronic pancreatitis. The series includes subjects from our prior report ${ }^{4}$ plus additional subjects recruited using similar criteria. We

Abbreviation used in this paper: CF, cystic fibrosis.

(C) 2001 by the American Gastroenterological Association 0016-5085/01/ \$35.00 doi:10.1053/gast.2001.29673 
examined them for rare CFTR mutations, for PSTI mutations, and for clinical and physiologic evidence of impaired extrapancreatic CFTR function. By correlating pancreatitis risk with reduced CFTR-mediated ion transport and related clinical features, this analysis has implications for the diagnosis, pathogenesis, and prevention of pancreatitis.

\section{Materials and Methods Study Subjects}

Our prior study examined 27 subjects who were identified by reviewing charts of patients referred to Duke University Medical Center from 1991 to 1996, as described. ${ }^{4}$ Briefly, each subject was white and had multiple episodes of abdominal pain with objective evidence of pancreatitis; we excluded patients with moderate alcohol use (over 15 drinks/ week at any time), hereditary pancreatitis by family history, or CF lung disease. ${ }^{4}$ When subsequent genetic testing diagnosed hereditary pancreatitis ${ }^{15}$ in 2 of the initial report's subjects (nos. 11 and 15), ${ }^{4}$ we recontacted them to further review their family histories and recognized that 1 case (no. 15) should have originally been excluded on this basis; therefore, 26 subjects from the prior report ${ }^{4}$ met the original entry criteria and were included in this series. In subsequent chart reviews, we focused on younger patients (diagnosed by age 50 years) and we screened potential new subjects for PRSS1 mutations before entry to avoid diluting the series of idiopathic cases with individuals who have hereditary pancreatitis. Using these modified entry criteria for pancreatitis patients seen at this medical center, 8 additional subjects were enrolled and 3 candidates were excluded because they had the R122H PRSS1 mutation; the family histories were negative for the 3 excluded candidates. In addition, we enrolled 3 patients who were referred from outside centers who met these entry criteria.
Two additional patients were tested who were referred from outside centers as known CF carriers with unexplained pancreatitis, nondiagnostic sweat tests, and normal chest radiographs. They were tested for rare CFTR mutations and for mutations of other genes; also, 1 of these subjects underwent clinical and physiologic evaluation studies (see below). They were excluded from the series for most prevalence ratio calculations because they were known to be $\mathrm{CF}$ carriers before referral. Thus, the full series contained 39 subjects, but most prevalence calculations were based on data for only 37 subjects. Table 1 summarizes how subgroups of subjects were recruited and tested.

\section{Molecular Analyses}

All subjects were screened for 17 CFTR mutations (including 5T) as described ${ }^{4}$ and were tested for D1152H by restriction enzyme digestion. In 20 subjects, including all 13 subjects with only one mutation detected by screening, we sequenced all CFTR exons and flanking regions (ABI310 Genetic Analyzer; Applied Biosystems, Foster City, CA). The sequenced group included 4 subjects with normal CFTR genotypes (by screening) who were selected based on their willingness to undergo physiologic testing (see below). Sequencing was not done in others with normal CFTR genotypes (by screening) because of cost.

We defined severe alleles $\left(\mathrm{CF}^{\text {sev }}\right)$ as those causing $\mathrm{CF}$ by current consensus criteria ${ }^{16}$; they cause classic CF in homozygotes $\left(\mathrm{CF}^{\mathrm{sev}} / \mathrm{CF}^{\mathrm{sev}}\right)$ and in compound heterozygotes who also have $\Delta \mathrm{F} 508\left(\Delta \mathrm{F} 508 / \mathrm{CF}^{\mathrm{sev}}\right)$. Mild-variable alleles $\left(\mathrm{CF}^{\mathrm{m}-\mathrm{v}}\right)$ cause variable phenotypes (e.g., congenital bilateral absence of the vas deferens) in compound heterozygotes with $\mathrm{CF}^{\mathrm{sev}}$ alleles $\left(\mathrm{CF}^{\mathrm{sev}} / \mathrm{CF}^{\mathrm{m}-\mathrm{v}}\right) . \mathrm{CF}^{\mathrm{m}-\mathrm{v}}$ includes mutations that sometimes cause classic CF (e.g., D1152H) and mutations that predispose to congenital bilateral absence of the vas deferens even though most compound heterozygotes are asymptomatic (e.g., 5T).

PSTI exons and flanking sequences were screened by denaturing high-performance liquid chromatography. ${ }^{17,18}$ N34S

Table 1. Subgroups of Subjects Based on Recruitment and Testing

\begin{tabular}{cl}
\hline $\begin{array}{l}\text { Subgroups based on recruitment } \\
39\end{array}$ & Total number of subjects in study. \\
26 & Number of subjects recruited for the initial study. ${ }^{4}$ \\
11 & For these, hereditary pancreatitis was excluded based on family history. \\
& Number of subjects recruited using similar inclusion criteria after the initial study. \\
2 & For these, hereditary pancreatitis was excluded based on PRSS1 genetic testing. \\
& Number of subjects who were known to be CF carriers before referral. \\
Subgroups based on testing & These subjects were excluded from most prevalence ratio calculations. \\
39 & \\
8 & Number of subjects screened for common CFR, PSTI, and PRSS1 mutations. \\
4 & Number of subjects who had comprehensive DNA sequencing of CFTR gene. \\
6 & Subjects who had 1 CF-causing mutation found by screening. \\
11 & Subjects who had only mild-variable (CFm-v) mutations identified by screening. \\
4 & Subjects who had 2 apparently normal CFTR alleles based on screening. \\
& Number of subjects who had physiologic and clinical testing (Table 4$).$ \\
\end{tabular}


heterozygotes and homozygotes were confirmed by sequencing exon 3 and restriction enzyme digestion ( $\mathrm{HpyCH} 4$ III); heterozygotes were further tested by sequencing the PSTI promoter, exons, and flanking sequences. To estimate the general prevalence of N34S, white patients with hemochromatosis or fragile $\mathrm{X}$ were screened by denaturing high-performance liquid chromatography and restriction enzyme digestion; N34S occurred in 4 of 426 control alleles $(0.9 \%)$.

For PRSS1, DNA was tested for R122H ("R117H”) by restriction enzyme digestion ${ }^{15}$ and for A16V ("A8V") and N29I ("N21I") by sequencing exon 2.19,20

\section{Physiologic and Clinical Studies}

Eleven subjects were selected for physiologic and clinical evaluation based on their willingness to participate. Nasal bioelectric responses were recorded to measure baseline potential differences and CFTR-mediated ion transport. ${ }^{21}$ Subjects were clinically assessed for respiratory and male reproductive findings. Laboratory studies included sweat testing, chest radiographs, spirometry, and sputum culture. Subjects provided separate informed consent for genetic and physiologic/clinical testing.

\section{Data Analysis}

Groups were compared using the Fisher exact or unpaired $t$ tests. The exact test was used for comparisons yielding prevalence ratios below 500 and the binomial distribution was used for comparisons involving very rare events (with prevalence ratios over 500). Means ( \pm SEM) and 2-tailed $P$ values are presented.

\section{Results}

\section{CFTR Mutations in Individual Subjects}

Twenty-six CFTR mutations were detected in 17 subjects (Table 2 ). There were 21 common mutations; 9 were severe (CF sev $^{\circ}$ F508, N1303K, 621+1G>T) and 12 were mild-variable $\left(\mathrm{CF}^{\mathrm{m}-\mathrm{v}}\right.$ : $\left.5 \mathrm{~T}, \mathrm{R} 117 \mathrm{H}\right)$. Among the 9 subjects with severe mutations (nominal CF carriers), 3

Table 2. Abnormal CFTR, PSTI, and PRSS1 Alleles Detected in 39 Patients With Chronic Pancreatitis

\begin{tabular}{|c|c|c|c|c|c|c|}
\hline No. & $\begin{array}{l}\text { Age } \\
\text { at Dx }\end{array}$ & Sex & $\begin{array}{l}\text { Abnormal CFTR } \\
\text { genotypes }\end{array}$ & $\begin{array}{l}\text { CFTR polymorphisms and } \\
\text { complex alleles }\end{array}$ & PSTI & PRSS1 \\
\hline 1 & 45 & M & $\Delta \mathrm{F} 508 / \mathrm{R} 117 \mathrm{H}-7 \mathrm{~T}$ & (Screened only) & N34S/- & $-/-$ \\
\hline 2 & 32 & $\mathrm{~F}$ & $\Delta \mathrm{F} 508 / 5 \mathrm{~T}$ & 11TG-5T-V470; I1027T & $-1-$ & $-/-$ \\
\hline 3 & 48 & $\mathrm{~F}$ & $\Delta \mathrm{F} 508 / 5 \mathrm{~T}$ & 12TG-5T-V470 & $-1-$ & $-1-$ \\
\hline $4^{b}$ & 8 & M & $\Delta \mathrm{F} 508 / \mathrm{D} 1152 \mathrm{H}$ & D1152H-V470 & $-1-$ & $-1-$ \\
\hline 5 & 15 & $\mathrm{~F}$ & $\Delta \mathrm{F} 508 / \mathrm{D} 1152 \mathrm{H}$ & D1152H-V470 & $-1-$ & $-/-$ \\
\hline 6 & 26 & $\mathrm{~F}$ & $\Delta \mathrm{F} 508 / \mathrm{P} 574 \mathrm{H}$ & None & $-1-$ & $-1-$ \\
\hline 7 & 40 & $\mathrm{~F}$ & $\Delta \mathrm{F} 508 / 3120 \mathrm{G}>\mathrm{A}$ & None & $-1-$ & $-1-$ \\
\hline $8^{b}$ & 16 & M & $621+1 G>T / G 1069 R$ & None & $-1-$ & $-1-$ \\
\hline 9 & 7 & $\mathrm{~F}$ & $5 \mathrm{~T} / 5 \mathrm{~T}$ & 13TG-5T/11TG-5T & N34S/- & $-1-$ \\
\hline 10 & 43 & M & N1303K/- & None & $-1-$ & $-1-$ \\
\hline 11 & 32 & $\mathrm{~F}$ & R117H-7T/- & $4005+117 T>G$ & $-1-$ & $-/-$ \\
\hline 12 & 33 & M & $5 \mathrm{~T} /-$ & 1716G $>$ A/12TG-5T-V470 & $-1-$ & $-1-$ \\
\hline 13 & 51 & M & $5 \mathrm{~T} /-$ & $11 \mathrm{TG}-5 \mathrm{~T}$ & $-1-$ & $-1-$ \\
\hline 14 & 29 & $\mathrm{~F}$ & $5 \mathrm{~T} /-$ & None & $-1-$ & $-1-$ \\
\hline 15 & 12 & $\mathrm{~F}$ & $5 \mathrm{~T} /-$ & None & $-1-$ & $-1-$ \\
\hline 16 & 30 & $\mathrm{~F}$ & $5 \mathrm{~T} /-$ & $1248+15 T>A / 11 T G-5 T$ & $-1-$ & $-1-$ \\
\hline 17 & 14 & M & $5 \mathrm{~T} /-$ & 12TG-5T-V470 & N34S/- & $-1-$ \\
\hline 18 & 12 & $\mathrm{~F}$ & $-1-$ & None & N34S/N34S & $-1-$ \\
\hline 19 & 46 & $\mathrm{~F}$ & $-1-$ & R75Q & N34S /- & $-1-$ \\
\hline 20 & 44 & $\mathrm{~F}$ & $-1-$ & None & N34S /- & $-1-$ \\
\hline 21 & 21 & $\mathrm{~F}$ & $-1-$ & (Screened only) & N34S/- & $-1-$ \\
\hline 22 & 47 & $\mathrm{~F}$ & $-/-$ & (Screened only) & N34S/- & $-1-$ \\
\hline 23 & 35 & M & $-1-$ & (Screened only) & N34S/- & $-1-$ \\
\hline 24 & 16 & $\mathrm{~F}$ & $-1-$ & R75Q & $-1-$ & $\mathrm{R} 122 \mathrm{H} /-$ \\
\hline
\end{tabular}

NOTE. Thirty-nine ICP patients were screened for common CFTR, PSTI, and PRSS1 mutations. The CFTR mutation panel included $\triangle$ F508, R117H, R334W, R347P, A455E, I507, G542X, S549N, G551D, R553X, R560T, D1152H, W1282X, N1303K, 621+1G >T, 1717-1G>A, 3849+10kb $\mathrm{C}>\mathrm{T}$ and the $5 \mathrm{~T}$ allele in intron 8. Most CFTR mutation screening data was previously reported for 16 subjects: nos. 1-3, 5, 7, 10-12, 14, 15, 18, 19, and 21-24. ${ }^{4}$ Twenty subjects were tested for rare CFTR mutations by sequencing all exons and flanking regions (nos. 2-20 and 24). Eight subjects were tested for rare PSTI mutations by sequencing all exons, flanking regions, and the promoter (nos. 1, 9, 17, and 19-23).

Dx, diagnosis.

al1027T, R75Q, and 1716G >A are noted because they may be associated with congenital bilateral absence of the vas deferens. ${ }^{22,28} 1248+$ 15T $>A$ is novel (significance unknown). Complex alleles cause greater loss of function than 5T alone (e.g., 13TG-5T, 12TG-5T, and 5T-V470).28 Mutations linked to V470 are noted because V470 reduces CFTR function by $40 \% .{ }^{28}$ Six subjects were heterozygous for V470 with undetermined linkage (nos. 10, 13-15, 19, and 24). All 20 sequenced subjects were tested for the above polymorphisms plus 2694T $>$ G (T854T), 4521G $>$ A (Q1463Q), 405+46G $>$ T, 875+40A $>$ G, IVS6a(GATT)6-7, and 1001+11C $>$ T.

${ }^{b}$ Before referral, subjects 4 and 8 were known to have the $\Delta \mathrm{F} 508$ or $621+1 \mathrm{G}>\mathrm{T}$ mutations with normal or borderline sweat testing, respectively. 
had common milder CFTR mutations (nos. 1-3), 5 had rare mutations that were detected by DNA sequencing (nos. 4-8), and 1 had a normal second CFTR allele based on DNA sequencing (no. 10). Each of the rare mutations detected in subjects $4-8$ is mild-variable: $\mathrm{D} 1152 \mathrm{H}$, P574H, G1069R, and 3120G $>$ A. ${ }^{22-25}$ No other rare mutations were found in the remaining 11 subjects who were tested by DNA sequencing.

\section{Compound Heterozygotes}

Nine subjects were compound heterozygotes. Eight had $\mathrm{CF}^{\mathrm{sev}} / \mathrm{CF}^{\mathrm{m}-\mathrm{v}}$ genotypes (nos. $1-8$ ) and 1 was $\mathrm{CF}^{\mathrm{m}-\mathrm{v}} / \mathrm{CF}^{\mathrm{m}-\mathrm{v}}$ (no. 9). None of the subjects had 2 severe mutations, as anticipated, because individuals with $\mathrm{CF}$ were excluded. Only 1 compound heterozygote's genotype was detectable by routine genetic testing (no. 1).

\section{Novel Mutations, Polymorphisms, and Complex Alleles}

One subject had a new mutation (no. 16; $1248+15 \mathrm{~T}>\mathrm{A}$; significance unknown). No polymorphism was especially frequent in pancreatitis; 3 of the detected polymorphisms may predispose to male infer- tility and might therefore be associated with partial loss of CFTR function (I1027T, 1716G > A, R75Q).22,26,27 The $5 \mathrm{~T}$ mutation often occurred in complex alleles (in cis) that cause greater loss of function than $5 \mathrm{~T}$ alone: TG13-5T (no. 9), TG12-5T-V470 (nos. 3, 12, and 17), and $5 \mathrm{~T}-\mathrm{V} 470$ (no. 2). ${ }^{28-31}$

\section{CFTR Allele and Genotype Prevalences}

Table 3 compares the observed versus expected frequencies of CFTR alleles and genotypes in the series. Pancreatitis is associated with severe mutations (5:1, observed:expected ratio). However, the more striking association is with $\mathrm{CF}^{\mathrm{sev}} / \mathrm{CF}^{\mathrm{m}-\mathrm{v}}$ genotypes (80:1).

Among the 9 subjects with severe mutations, 8 had mild-variable mutations (16:1); only $1 \mathrm{CF}$ carrier had a normal allele (no. 10). Compound heterozygotes (nos. 1-9) accounted for most detected severe (8/9) and mildvariable (10/17) mutations. After excluding compound heterozygotes, pancreatitis was no longer significantly associated with severe (1/29) or mild-variable (7/29) mutations. There also was no association with $5 \mathrm{~T}$ after excluding subjects with complex alleles containing $5 \mathrm{~T}$ $(4 / 33)$.

Table 3. Prevalence Ratios for CFTR Mutations and Genotypes in Idiopathic Chronic Pancreatitis

\begin{tabular}{|c|c|c|c|}
\hline \multirow[b]{2}{*}{ Genotypes or alleles } & \multicolumn{2}{|c|}{ Frequencies } & \multirow[b]{2}{*}{ Ratio (observed:expected) } \\
\hline & Expected $^{a}$ & Observed $^{b}$ & \\
\hline \multicolumn{4}{|l|}{ Abnormal CFTR alleles } \\
\hline $\mathrm{CF}^{\mathrm{sev}}$ (severe) & $1 / 57$ & $7 / 74$ & $5.3[2.5-11.7], P=0.0006$ \\
\hline $\mathrm{CF}^{\mathrm{m}-\mathrm{v}}$ (mild-variable) & $1 / 18$ & $17 / 74$ & 4.1 [2.6-6.5], $P<0.0001$ \\
\hline 5T (most common $\mathrm{CF}^{\mathrm{m}-\mathrm{v}}$ ) & $1 / 20$ & $10 / 74$ & $2.6[1.5-5.0], P<0.005$ \\
\hline \multicolumn{4}{|l|}{ Abnormal CFTR genotypes } \\
\hline Compound heterozygotes & $1 / 204$ & $7 / 37$ & 39 [14-105], $P<0.0001$ \\
\hline $\mathrm{CF}^{\mathrm{sev}} / \mathrm{CF}^{\mathrm{m}-\mathrm{v}}$ & $1 / 509$ & $6 / 37$ & 83 [21-318], $P<0.0001$ \\
\hline \multicolumn{4}{|l|}{ Abnormal PSTI alleles } \\
\hline N34S & 11/1764 & $10 / 74$ & 22 [10-49], $P<0.0001$ \\
\hline In subjects Dx'd by age 21 & $"$ & $5 / 18$ & 45 [17-115], $P<0.0001$ \\
\hline In subjects Dx'd after age 21 & $"$ & $5 / 56$ & 14 [5-40], $P<0.0001$ \\
\hline CFTR compound heterozygote + N34S & $1 / 16400$ & $2 / 37$ & $900, P<0.0001$ \\
\hline \multicolumn{4}{|l|}{ Subset analyses } \\
\hline $\mathrm{CF}^{\mathrm{m}-\mathrm{v}}$, if $\mathrm{CF}^{\mathrm{sev}}$ present & $1 / 18$ & $8 / 9$ & 16 [13-20], $P<0.0001$ \\
\hline N34S, if CFTR compound heterozygote & $11 / 1764$ & $2 / 18$ & $18[4-75], P=0.007$ \\
\hline
\end{tabular}

NOTE. Subject numbers and genotypes are listed in Table 2. Abnormal CFTR alleles cause either severe (CFsev) or mild-variable loss of function $\left(\mathrm{CF}^{\mathrm{m}-\mathrm{v}}\right)$. Observed:expected ratios and 95\% confidence intervals (in brackets) were calculated by the Fisher exact test when possible. For ratios over $500, P$ values were calculated using the binomial distribution.

Dx'd, diagnosed.

aThe expected frequency of mutations was estimated assuming that the frequency of CF in U.S. Whites is $1 / 3200,51$ that the total allele frequency for $\mathrm{CF}^{\mathrm{sev}}$ mutations is $1 / 3200^{0.5}$, and that the allele frequencies for $5 \mathrm{~T}$ and $\mathrm{R} 117 \mathrm{H}$ are $5 \% 23,24,52$ and $0.2 \%, 53,54$ respectively. Allele prevalence data is unavailable for other $\mathrm{CF}^{\mathrm{m}-\mathrm{v}}$ alleles; in congenital bilateral absence of the vas deferens, their combined prevalence is less than for $\mathrm{R} 117 \mathrm{H}^{24,26,27}$ and we assumed that their combined prevalence in U.S. Whites is $0.4 \%$. For the N34S PSTI mutation, the expected allele frequency was calculated by combining data from 3 prior studies $(7 / 1338 \text { alleles, total })^{10,11,32}$ with data for control subjects in this study $(4 / 426$ alleles). To estimate expected frequencies containing multiple alleles, we assumed that each occurred independently $\left(\mathrm{e} . \mathrm{g}\right.$., $\mathrm{CF}^{\mathrm{sev}} / \mathrm{CF}^{\mathrm{m}-\mathrm{v}}=$ $(2)(1 / 18)(1 / 56.6)=1 / 509)$.

${ }^{b} \mathrm{~A}$ total of 26 abnormal CFTR alleles were detected among 78 tested alleles in 39 patients. However, because 2 subjects were known to have CFsev mutations before enrollment (nos. 4 and 8), their data was excluded from most calculations to avoid ascertainment bias. These 2 subjects were only included in the subset analyses at the bottom of the table. 


\section{PSTI Mutations}

The N34S PSTI mutation occurred in 10 of 78 alleles from study subjects $(21: 1 ; P<0.0001)$. One subject was $\mathrm{N} 34 \mathrm{~S}$ homozygous, and 8 were heterozygotes with 1 verified normal PSTI allele. Thus, N34S carrier status is sufficient to increase pancreatitis risk. Other potential PSTI mutations (M1T, L14P, D50E, P55S, IVS2-23A $>\mathrm{T}$, and IVS3 $+2 \mathrm{~T}>\mathrm{C})^{10,11,32}$ were absent.

Two of 9 CFTR compound heterozygotes with pancreatitis had N34S $(18: 1 ; P<0.01)$. Assuming independent inheritance of CFTR and PSTI genotypes, these 2 examples suggest that pancreatitis risk is increased approximately 900-fold in N34S carriers who are CFTR compound heterozygotes.

\section{PRSS1 Mutations}

The R122H PRSS1 mutation occurred in 1 subject who was enrolled when we were excluding hereditary pancreatitis (pre-entry) based only on family history data (no. 24). Anamnestic data for this subject indicated that she had no relatives with pancreatitis. For subjects recruited after 1996, hereditary pancreatitis was excluded before entry by PRSS1 testing. Accordingly, R122H and other known PRSS1 mutations were absent in all patients in the series other than no. 24.

\section{Clinical and Physiologic Features}

The mean age at diagnosis was $33.2 \pm 2.5$ years $(\mathrm{n}=39)$, and 11 subjects were diagnosed by age 21 years.
Subjects 2, 3, 4, and 8 each had 1 relative with pancreatitis. The affected sister of subject 8 had the genotype $621+1 \mathrm{G}>\mathrm{T} / \mathrm{G} 1069 \mathrm{R}$; DNA was not available for the other 3 affected relatives. Subjects with any mutation (no. $1-24)$ were younger than others at diagnosis $(29.3 \pm 2.9$ vs. $39.5 \pm 4.2 ; P<0.05)$. Pancreatogram findings were equally severe in subjects with or without mutations.

Table 4 compares physiologic data for the tested subjects who had 0 vs. 2 CFTR mutations. Five of these subjects had PSTI or PRSS1 mutations; the physiologic parameters were unaffected by these mutations. (Subjects were selected for physiologic testing before testing for PSTI mutations was possible.) Baseline nasal potential difference (PD) values, which reflect basal $\mathrm{Na}^{+}$transport, were normal and did not correlate with the number of CFTR mutations.

\section{CFTR-Mediated Chloride Transport}

$\triangle \mathrm{PD}$ values (in $\mathrm{mV}$ ) correlated with CFTR genotypes in subjects with 0 vs. 2 mutations (Figure 1). When compared with historical data, ${ }^{21}$ subjects with no mutations resembled normal controls. In compound heterozygotes, CFTR-mediated chloride transport was lower than in normal controls $(P<0.0001)$ or in subjects without mutations $(P<0.01)$, but higher than in individuals with $\mathrm{CF}(P<0.002){ }^{21}$

\section{Sweat Testing}

Sweat chloride values were normal in subjects with normal CFTR genotypes who had PRSS1 or PSTI

Table 4. Clinical and Physiologic Data for 11 Patients With Pancreatitis

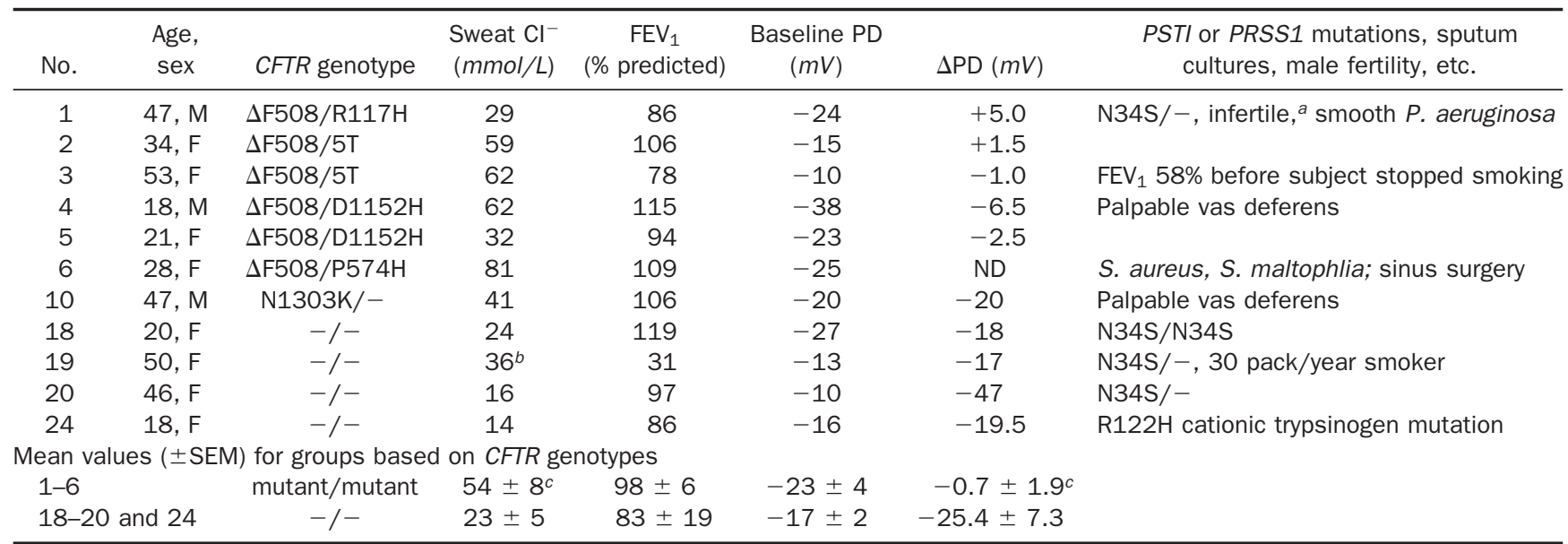

NOTE. Subject numbers and genotyping data are from Table 2. This table shows age at testing (not age at diagnosis). Each subject's chest radiograph was normal except for basilar linear atelectasis in no. 1 and hyperinflation in subjects 13 and 19. Some data was previously reported for subjects 1-3.4 Subject 3 was retested after she stopped smoking. Other subjects were nonsmokers except as noted.

a Subject 1 was infertile because of congenital bilateral absence of the vas deferens. Subjects 4 and 10 had a palpable vas deferens and subject 10 had offspring.

${ }^{b}$ This value is based on 1 measurement; other values are means of at least 2 sweat tests.

cSubjects with 2 CFTR mutations were significantly different from subjects with no mutations based on sweat $\mathrm{Cl}^{-}$and $\Delta \mathrm{PD}$ values $(P<0.02$ for each comparison). 


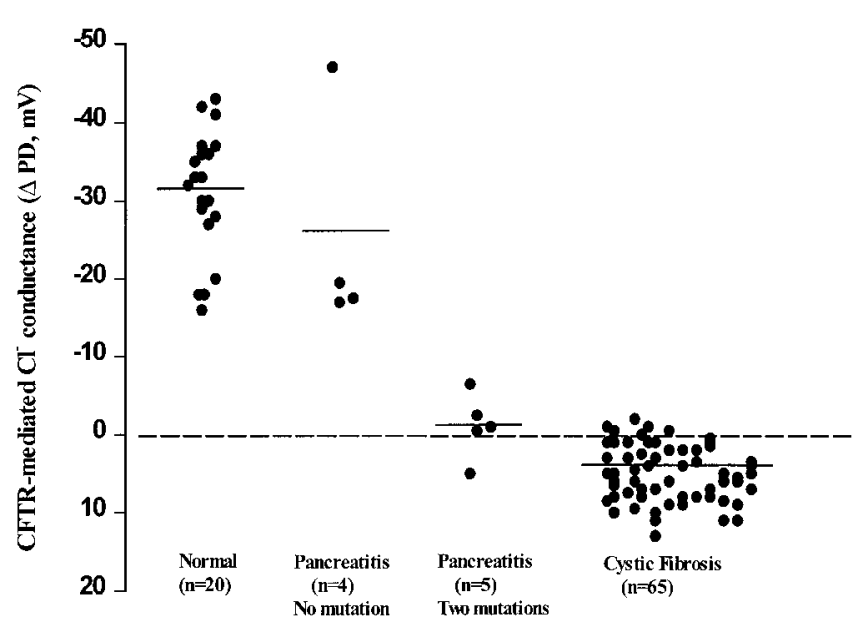

Figure 1. CFTR function in the nasal epithelium in genotyped subjects with pancreatitis. CFTR-mediated $\mathrm{Cl}^{-}$conductance $(\Delta \mathrm{PD})$ was measured in subjects with pancreatitis who had 0 vs. 2 CFTR mutations, and compared with published values for normal controls and for individuals with classic cystic fibrosis. ${ }^{20}$ Subjects with CFTR-related pancreatitis (i.e., those with 2 mutations) differed significantly from subjects without CFTR mutations, from normal controls, and from individuals with CF based on their $\triangle \mathrm{PD}$ values $(P<0.01$ for each comparison). This indicates that these subjects had less CFTR-mediated ion transport than normal but that this loss of function was less severe than in cystic fibrosis. One study subject with a CF-causing mutation had a normal second CFTR allele based on DNA sequencing; his $\triangle P D$ value of $-20 \mathrm{mV}$ (not shown) was normal, as anticipated based on published data for obligate $\mathrm{CF}$ carriers. ${ }^{32}$

mutations. By contrast, subjects with 2 CFTR mutations had higher mean sweat chloride values $(54 \pm 8, P<$ 0.02). Even though these subjects each had at least 2 normal or borderline sweat chloride values in the past, 3 of them had values above $60 \mathrm{mmol} / \mathrm{L}$ when last tested (Table 4).

\section{Respiratory Findings}

No subject had CF lung disease (Table 4). Nonetheless, 2 compound heterozygotes produced sputum containing CF-associated bacteria (nos. 1 and 6); in both, spirometry was normal and bronchiectasis was absent. One compound heterozygote (no. 6) had severe recurrent sinusitis requiring a Caldwell-Luc procedure; others (nos. 1 and 3) had milder sinusitis.

\section{Fertility in Males}

One compound heterozygote had congenital bilateral absence of the vas deferens (no. 1); another had a palpable vas bilaterally (no. 4).

\section{Features of the CF Carrier}

One subject in the series was a CF carrier who had 1 normal CFTR allele based on DNA sequencing (no. 10). He had normal baseline and $\Delta P D$ values (Table 4 ), as anticipated based on published data for obligate CF carriers. ${ }^{33}$ He had a palpable vas deferens bilaterally, has fathered children, and had no respiratory findings suggesting reduced CFTR function.

\section{Discussion}

This study shows that idiopathic chronic pancreatitis is often associated with having 2 CFTR mutations or 1 PSTI mutation. These genotypes occurred in many cases diagnosed by age 50 years (16/32 after excluding hereditary pancreatitis) and in most diagnosed by 21 years old (7/10). Pancreatitis risk was highest in those with 2 CFTR mutations plus N34S.

For CFTR, the greatest risk of pancreatitis is associated with compound heterozygote genotypes containing 1 severe mutation plus 1 mild-variable mutation. The mild-variable mutations in these genotypes account for the residual CFTR function $(5 \%-25 \%)$ that protects these individuals from CF lung disease ${ }^{24}$ and that may also be required for pancreatitis to occur. ${ }^{34}$ Because mildvariable mutations are generally excluded from mutation panels used for CF testing, routine genetic testing would incorrectly classify most compound heterozygote pancreatitis patients as carriers; this explains why we found a higher frequency of CFTR compound heterozygotes than others who tested only for common mutations. ${ }^{5-9}$ Thus, even though pancreatitis risk is increased in individuals identified as carriers by routine genetic testing, more complete testing of a series of such nominal carriers with pancreatitis showed that most were compound heterozygotes who had initially undetected mutations. This is the main finding of the present study; it suggests autosomal recessive inheritance for most CFTR-related pancreatitis risk and implicates reduced CFTR function in pathogenesis.

A primary goal of this study was to thoroughly test a series of subjects with pancreatitis who have common CF-causing mutations to determine whether their second CFTR allele contains an uncommon mutation that was initially undetected. We tested for these uncommon mutations by DNA sequencing because it is more sensitive than the screening methods previously used to study pancreatits ${ }^{4-9}$ and other nonpulmonary CFTRrelated diseases. ${ }^{22-26,35-37}$ Because some subjects in this study (a minority) were not tested by DNA sequencing, it is possible that our data underestimated the prevalence of genotypes containing only mutations that were absent in the mutation panel used for screening (e.g., $\mathrm{CF}^{\mathrm{m}-\mathrm{v}}$ / $\mathrm{CF}^{\mathrm{m}-\mathrm{v}}$ genotypes).

This study found mild-variable CFTR mutations in most pancreatitis patients with abnormal genotypes. The predominant mild-variable mutation in pancreatitis was 
5T. This mutation causes inefficient splicing of exon 10 leading to production of nonfunctional copies of CFTR. ${ }^{38}$ $5 \mathrm{~T}$ occurred in $13 \%$ of pancreatitis alleles vs. $5 \%$ in the general population and vs. $12 \%-20 \%$ in congenital bilateral absence of the vas deferens. ${ }^{22,24,26}$ Our data contrasts with prior studies reporting no association of $5 \mathrm{~T}$ with pancreatitis. ${ }^{5-7,9}$ The higher $5 \mathrm{~T}$ prevalence in our study may partly result from including subjects with juvenile-onset disease and excluding individuals reporting moderate alcohol use. In any case, our data suggests that 5T-related pancreatitis risk is largely caused by 5T occurring either in complex alleles ${ }^{28-31}$ or in CFTR compound heterozygote genotypes. This study's physiologic findings also correlate CFTR loss of function with pancreatitis risk. CFTR-mediated chloride transport in the nasal epithelium ( $\triangle \mathrm{PD}$ ) was abnormal in compound heterozygotes but normal in subjects without CFTR mutations. Nonetheless, compound heterozygotes differed from $C F$ patients in that their $\triangle \mathrm{PD}$ values were less abnormal and their baseline PD values were normal; both findings reflect CFTR loss of function between that in $\mathrm{CF}$ $(>95 \%)$ and in carriers $(50 \%)$. By contrast, the $1 \mathrm{CF}$ carrier in the series (no. 10) had a normal $\Delta \mathrm{PD}$ value, as is typical of obligate CF carriers. ${ }^{33}$ Because the prevalence of CF carriers was not increased in the series, this individual may have been ascertained by chance, alone.

Finally, the link between pancreatitis risk and CFTR loss of function is supported by extrapancreatic clinical findings observed in compound heterozygotes. These are reminiscent of findings associated with congenital bilateral absence of the vas deferens $23,25,26,35,36$ and include abnormal sweat testing, bronchitis with sputum containing CF-typical pathogens, and sinusitis. The absence of CF lung disease was anticipated because no subject had 2 severe mutations ${ }^{24}$; the variable expression of vas deferens disease was also anticipated based on the incomplete penetrance of infertility in males with $\mathrm{CF}^{\mathrm{sev}} / \mathrm{CF}^{\mathrm{m}-\mathrm{v}}$ genotypes (approximately 20\%). ${ }^{39}$

There are many parallels between CFTR-related pancreatitis and congenital bilateral absence of the vas deferens. ${ }^{40}$ Both diseases are usually sporadic, delaying recognition of their heritability. Both were initially associated with CF carrier status; however, further study revealed their closer association with compound heterozygosity and with mild-variable mutations initially classified as benign polymorphisms (e.g., 5T). As in congenital bilateral absence of the vas deferens, ${ }^{39}$ there seems to be incomplete penetrance for pancreatitis in CFTR compound heterozygotes, implicating gene-gene or gene-environment interactions in pathogenesis. In other words, since most CFTR compound heterozygotes do not develop pancreatitis, other genetic or environmental factors must also be important in determining this phenotype.

More generally, the relationship between CF carrier status and pancreatitis suggests a novel paradigm for genetic predisposition in which mild mutations of a recessive Mendelian disease gene (CFTR) increase the risk of a seemingly unrelated disease (pancreatitis). ${ }^{40}$ Based on this example, we speculate that mild or atypical mutations of other Mendelian disease genes may play similar roles in other complex diseases.

For gastroenterologists, there also are pertinent parallels between CFTR-related pancreatitis and some forms of cholestasis with respect to genetic predisposition: The liver resembles the pancreas in that CFTR occurs mainly in the apical membranes of duct cells where it normally promotes bicarbonate and fluid secretion into the duct lumen. ${ }^{41-43}$ This suggests that reduced CFTR function might predispose to hepatobiliary disease, and this suggestion is supported by recent data associating reduced nasal CFTR-mediated chloride transport with sclerosing cholangitis. ${ }^{44}$

This study also examined how PSTI mutations influence pancreatitis risk. It was already known that having the N34S PSTI mutation predisposes to childhood pancreatitis; even though most children with N34S do not develop pancreatitis, the risk of pancreatitis is increased in those who have this mutation. ${ }^{10,11}$ Our findings show that this association also applies to adults with idiopathic chronic pancreatitis.

We also found that $\mathrm{N} 34 \mathrm{~S}$ carrier status and CFTR compound heterozygosity had additive effects on pancreatitis risk. Because subjects with only N34S (nos. 18-20) had normal CFTR-mediated ion transport and no clinical evidence of reduced extrapancreatic CFTR function, this study's genetic, physiologic, and clinical findings indicate that PSTI and CFTR mutations act separately to increase pancreatitis risk. One implication of these findings is that intrapancreatic protease activation may contribute to the pathogenesis of CFTR-related pancreatitis. A related implication is that $\mathrm{N} 34 \mathrm{~S}$ carrier status may help explain the occasional occurrence of pancreatitis in individuals with CF or congenital bilateral absence of the vas deferens.

The effect of PSTI and CFTR mutations on pancreatitis risk has important implications for pathogenesis and prevention. Because PSTI and CFTR occur in acinar and ductal cells, respectively, this effect identifies these sites as distinct targets for interventions aiming to reduce pancreatitis risk. Specifically, susceptible individuals may benefit from promoting ductal bicarbonate secre- 
tion $^{41}$ and from reducing intra-acinar trypsinogen activation. ${ }^{11}$

This study also has implications for clinical practice. For PRSS1, we identified one apparently sporadic case of hereditary pancreatitis in the series and 3 additional sporadic cases were excluded among younger candidates considered for this study. Current clinical practice relies on family history data to identify potential cases of hereditary pancreatitis, ${ }^{19,45,46}$ but the occurrence of such sporadic cases implies that a negative family is not sufficient to exclude the diagnosis of hereditary pancreatitis.

The frequency of CFTR, PSTI, and PRSS1 mutations in chronic pancreatitis suggests that some patients with this condition may benefit from genetic testing. Because initial reports have not associated alcoholic pancreatitis with these mutations, $8,32,47,48$ genetic testing may help distinguish between alcohol-related and idiopathic cases; detection of mutations may improve medical care and patient satisfaction in cases where physicians might otherwise suspect undisclosed alcoholism. Moreover, when causative PRSS1 mutations are detected, the correct diagnosis is hereditary pancreatitis, a disease that differs from idiopathic pancreatitis because it leads to pancreatic adenocarcinoma with a cumulative risk approaching $40 \% .{ }^{49}$ Surveillance may permit early cancer detection in these individuals.

For CFTR, there is currently no consensus about the role of genetic testing in idiopathic chronic pancreatitis. ${ }^{50}$ Even though current treatment for chronic pancreatitis is the same regardless of whether CFTR mutations are found, some patients will wish to be tested so they can better understand their disease. Others will wish to know if they are carriers for CF before having children.

When CFTR genetic testing is done in pancreatitis patients, the results will require cautious interpretation. Rare pancreatitis patients will have 2 detected CFTR mutations. This group will include patients with unrecognized classic CF in whom pancreatitis precedes overt lung disease; most will have diagnostic sweat tests and may benefit from specialized pulmonary care. More often, genetic testing will detect only 1 mutation. In these cases, the presence of associated findings (borderline sweat testing, male infertility, abnormal nasal bioelectric responses, etc.) should suggest CFTR compound heterozygosity. In these cases, compound heterozygosity might be confirmed by $5 \mathrm{~T}$ testing; however, most such cases will have mild-variable mutations that are undetectable using widely available CFTR genetic testing methods.
In summary, most patients with idiopathic chronic pancreatitis had mutations of at least 1 tested gene. Occasionally, pancreatitis occurred as a sporadic condition caused by PRSS1 mutations; more often, susceptibility to pancreatitis resulted from CFTR compound heterozygosity and PSTI carrier status. Genetic, clinical, and physiologic data indicate that CFTR and PSTI mutations influence pancreatitis risk through independent mechanisms. Genetic testing may be useful in selected patients with chronic pancreatitis.

\section{References}

1. Steer ML, Waxman I, Freedman S. Chronic pancreatitis. N Engl J Med 1995;332:1482-1490.

2. Owyang $C$. Chronic pancreatitis. In: Yamada T, Alpers DH, Owyang C, Powell DW, Silverstein FE, eds. Textbook of gastroenterology. 3rd ed. New York: Lippincott, 1999:2151-2177.

3. Liddle RA, Cohn JA. Hereditary diseases of the pancreas. In: Yamada T, Alpers DH, Owyang C, Powell DW, Silverstein FE, eds. Textbook of gastroenterology. 3rd ed. New York: Lippincott; 1999:2229-2243.

4. Cohn JA, Friedman KJ, Noone PG, Knowles MR, Silverman LM, Jowell PS. Relation between mutations of the cystic fibrosis gene and idiopathic pancreatitis. N Engl J Med 1998;339:653-658.

5. Sharer N, Schwarz M, Malone G, Howarth A, Painter J, Super M, Braganza J. Mutations of the cystic fibrosis gene in patients with chronic pancreatitis. N Engl J Med 1998;339:645-652.

6. Castellani C, Bonizzato A, Rolfini R, Frulloni L, Cavallini GC, Mastella G. Increased prevalence of mutations of the cystic fibrosis gene in idiopathic chronic and recurrent pancreatitis (letter). Am J Gastroenterol 1999;94:1993-1995.

7. Arduino C, Gallo M, Brusco A, Garnerone S, Piana MR, Di Maggio S, Promis GG, Ferrone M, Angeli A, Gaia E. Polyvariant mutant CFTR genes in patients with chronic pancreatitis. Clin Genet 1999;56:400-404.

8. Choudari CP, Lehman GA, Sherman S. Pancreatitis and cystic fibrosis gene mutations. Gastroenterol Clin North Am 1999;28: 543-549.

9. Ockenga J, Stuhrmann M, Ballmann M, Teich N, Keim V, Dork T, Manns MP. Mutations of the cystic fibrosis gene, but not cationic trypsinogen gene, are associated with recurrent or chronic idiopathic pancreatitis. Am J Gastroenterol 2000;95:2061-2067.

10. Witt H, Luck W, Hennies HC, Classen M, Kage A, Lass U, Landt $\mathrm{O}$, Becker M. Mutations in the gene encoding the serine protease inhibitor, Kazal type 1, are associated with chronic pancreatitis. Nat Genet 2000;25:213-216.

11. Pfutzer RH, Barmada MM, Brunskill AP, Finch R, Hart PS, Neoptolemos J, Furey WF, Whitcomb DC. SPINK1/PSTI polymorphisms act as disease modifiers in familial and idiopathic chronic pancreatitis. Gastroenterology 2000;119:615-623.

12. Naruse S, Kitagawa M, Ishiguro $\mathrm{H}$. Molecular understanding of chronic pancreatitis: a perspective on the future. Mol Med Today 1999;5:493-499.

13. Cohn JA, Melhus O, Page LJ, Dittrich KL, Vigna SR. CFTR: development of high-affinity antibodies and localization in sweat gland. Biochem Biophys Res Commun 1991;181:36-43.

14. Ockenga J, Dork T, Stuhrmann M. Low prevalence of SPINK1 gene mutations in adult patients with chronic idiopathic pancreatitis (letter). J Med Genet 2001;38:243-244.

15. Whitcomb DC, Gorry MC, Preston RA, Furey W, Sossenheimer MJ, Ulrich CD, Martin SP, Gates LK, Amann ST, Toskes PP, Liddle R, McGrath K, Uomo G, Post JC, Ehrlich GD. Hereditary pancreatitis 
is caused by a mutation in the cationic trypsinogen gene. Nat Genet 1996;14:141-145.

16. Rosenstein BJ, Cutting GR. The diagnosis of cystic fibrosis: a consensus statement. Cystic Fibrosis Foundation Consensus Panel. J Pediatr 1998;132:589-595.

17. Underhill PA, Jin L, Lin AA, Mehdi SQ, Jenkins T, Vollrath D, Davis RW, Cavalli-Sforza LL, Oefner PJ. Detection of numerous Y chromosome biallelic polymorphisms by denaturing high-performance liquid chromatography. Genome Res 1997;7:996-1005.

18. O'Donovan MC, Oefner PJ, Roberts SC, Austin J, Hoogendoorn B, Guy C, Speight G, Upadhyaya M, Sommer SS, McGuffin P. Blind analysis of denaturing high-performance liquid chromatography as a tool for mutation detection. Genomics 1998;52:44-49.

19. Witt H, Luck W, Becker M. A signal peptide cleavage site mutation in the cationic trypsinogen gene is strongly associated with chronic pancreatitis. Gastroenterology 1999;117:7-10.

20. Gorry MC, Gabbaizedeh D, Furey W, Gates LK, Jr, Preston RA, Aston CE, Zhang Y, Ulrich C, Ehrlich GD, Whitcomb DC. Mutations in the cationic trypsinogen gene are associated with recurrent acute and chronic pancreatitis. Gastroenterology 1997;113: 1063-1068.

21. Knowles MR, Paradiso AM, Boucher RC. In vivo nasal potential difference: techniques and protocols for assessing efficacy of gene transfer in cystic fibrosis. Hum Gene Ther 1995;6:445455.

22. Claustres M, Guittard C, Bozon D, Chevalier F, Verlingue C, Ferec C, Girodon E, Cazeneuve C, Bienvenu T, Lalau G, Dumur V, Feldmann D, Bieth E, Blayau M, Clavel C, Creveaux I, Malinge MC, Monnier N, Malzac P, Mittre H, Chomel JC, Bonnefont JP, Iron A, Chery M, Georges MD. Spectrum of CFTR mutations in cystic fibrosis and in congenital absence of the vas deferens in France. Hum Mutat 2000;16:143-156.

23. Costes B, Girodon E, Ghanem N, Flori E, Jardin A, Soufir JC, Goossens M. Frequent occurrence of the CFTR intron 8 (TG)n 5T allele in men with congenital bilateral absence of the vas deferens. Eur J Hum Genet 1995;3:285-293.

24. Chillon M, Casals T, Mercier B, Bassas L, Lissens W, Silber S, Romey MC, Ruiz-Romero J, Verlingue C, Claustres M, Nunes V, Ferec C, Estivill X. Mutations in the cystic fibrosis gene in patients with congenital absence of the vas deferens. N Engl J Med 1995;332:1475-1480.

25. Colin AA, Sawyer SM, Mickle JE, Oates RD, Milunsky A, Amos JA. Pulmonary function and clinical observations in men with congenital bilateral absence of the vas deferens. Chest 1996;110:440445.

26. Dork T, Dworniczak B, Aulehla-Scholz C, Wieczorek D, Bohm I, Mayerova A, Mayerova A, Seydewitz HH, Nieschlag E, Meschede $D$, Horst J, Pander HJ, Sperling H, Ratjen F, Passarge E, Schmidtke J, Stuhrmann M. Distinct spectrum of CFTR gene mutations in congenital absence of vas deferens. Hum Genet 1997;100:365-377.

27. Mak V, Zielenski J, Tsui LC, Durie P, Zini A, Martin S, Longley TB, Jarvi KA. Proportion of cystic fibrosis gene mutations not detected by routine testing in men with obstructive azoospermia. JAMA 1999;281:2217-2224.

28. Cuppens $\mathrm{H}$, Lin W, Jaspers $\mathrm{M}$, Costes $\mathrm{B}$, Teng $\mathrm{H}$, Vankeerberghen A, Jorissen M, Droogmans G, Reynaert I, Goossens M, Nilius B, Cassiman JJ. Polyvariant mutant cystic fibrosis transmembrane conductance regulator genes. The polymorphic $(\mathrm{Tg}) \mathrm{m}$ locus explains the partial penetrance of the T5 polymorphism as a disease mutation. J Clin Invest 1998:101:487-496.

29. Pagani F, Buratti E, Stuani C, Romano M, Zuccato E, Niksic M, Giglio L, Faraguna D, Baralle FE. Splicing factors induce cystic fibrosis transmembrane regulator exon 9 skipping through a nonevolutionary conserved intronic element. J Biol Chem 2000; 275:21041-21047.

30. Niksic M, Romano M, Buratti E, Pagani F, Baralle FE. Functional analysis of cis-acting elements regulating the alternative splicing of human CFTR exon 9. Hum Mol Genet 1999;8:2339-2349.

31. Noone PG, Pue CA, Zhou Z, Friedman KJ, Wakeling EL, Ganeshananthan M, Simon RH, Silverman LM, Knowles MR. Lung disease associated with the IVS8 5T allele of the CFTR gene. Am J Respir Crit Care Med 2000;162:1919-1924.

32. Chen JM, Ferec C. Molecular basis of hereditary pancreatitis. Eur J Hum Genet 2000;8:473-479.

33. Wilson DC, Ellis L, Zielenski J, Corey M, Ip WF, Tsui LC, Tullis E, Knowles MR, Durie PR. Uncertainty in the diagnosis of cystic fibrosis: possible role of in vivo nasal potential difference measurements. J Pediatr 1998;132:596-599.

34. Durie PR. Pancreatic aspects of cystic fibrosis and other inherited causes of pancreatic dysfunction. Med Clin North Am 2000;84: 609-620.

35. Dumur V, Gervais R, Rigot JM, Delomel-Vinner E, Decaestecker B, Lafitte JJ, Roussel P. Congenital bilateral absence of the vas deferens (CBAVD) and cystic fibrosis transmembrane regulator (CFTR): correlation between genotype and phenotype. Hum Genet 1996;97:7-10.

36. Kerem E, Raveharel N, Augarten A, Madgar I, Nissimrafinia M, Yahav Y, Goshen R, Bentur L, Rivlin J, Aviram M, Genem A, Chibafalek O, Kraemer MR, Simon A., Branski D, Kerem B. A cystic fibrosis transmembrane conductance regulator splice variant with partial penetrance associated with variable cystic fibrosis presentations. Am J Respir Crit Care Med 1997;155:19141920.

37. Wang X, Moylan B, Leopold DA, Kim J, Rubenstein RC, Togias A, Proud D, Zeitlin PL, Cutting GR. Mutation in the gene responsible for cystic fibrosis and predisposition to chronic rhinosinusitis in the general population. JAMA 2000;284:1814-1819.

38. Strong TV, Wilkinson DJ, Mansoura MK, Devor DC, Henze K, Yang Y, Wilson JM, Cohn JA, Dawson DC, Frizzell RA, Collins FS. Expression of an abundant alternatively spliced form of the cystic fibrosis transmembrane conductance regulator (CFTR) gene is not associated with a cAMP-activated chloride conductance. Hum Mol Genet 1993;2:225-230.

39. Shin D, Gilbert F, Goldstein M, Schlegel PN. Congenital absence of the vas deferens: incomplete penetrance of cystic fibrosis gene mutations. J Urol 1997;158:1794-1798.

40. Friedman KJ, Silverman LM. Cystic fibrosis syndrome: a new paradigm for inherited disorders and implications for molecular diagnostics. Clin Chem 1999;45:929-931.

41. Marino CR, Matovcik LM, Gorelick FS, Cohn JA. Localization of the cystic fibrosis transmembrane conductance regulator in pancreas. J Clin Invest 1991;88:712-716.

42. Fitz JG, McGill JM, Basavapa S, Melhus O, Cohn JA. Regulation of membrane chloride channels in rat bile ductular epithelial cells. J Clin Invest 1993;91:319-328.

43. Cohn JA, Strong TV, Picciotto M, Nairn AC, Collins FS, Fitz JG. Localization of the cystic fibrosis transmembrane conductance regulator in human bile duct epithelial cells. Gastroenterology 1993;105:1857-1864.

44. Sheth SG, Bishop MD, Shea JC, Hopper IK, Chopra S, Ellis L, Durie PR, Freedman SD. Primary sclerosing cholangitis is associated with abnormalities in cystic fibrosis-mediated chloride channel function (abstr). Gastroenterology 2000;118:A958.

45. Creighton J, Lyall R, Wilson DI, Curtis A, Charnley R. Mutations of the cationic trypsinogen gene in patients with chronic pancreatitis (letter). Lancet 1999;354:42-43.

46. Teich N, Hoffmeister A, Keim V. Mutations of cationic trypsinogen in chronic pancreatitis (letter). Lancet 1999;354:1302.

47. Teich N, Mossner J, Keim V. Screening for mutations of the cationic trypsinogen gene: are they of relevance in chronic alcoholic pancreatitis? Gut 1999;44:413-416.

48. Norton ID, Apte MV, Dixson H, Trent RJ, Haber PS, Pirola RC, 
Wilson JS. Cystic fibrosis genotypes and alcoholic pancreatitis. J Gastroenterol Hepatol 1998;13:496-499.

49. Lowenfels AB, Maisonneuve P, DiMagno EP, Elitsur Y, Gates LK, Perrault J, Whitcomb DC. Hereditary pancreatitis and the risk of pancreatic cancer. International Hereditary Pancreatitis Study Group. J Natl Cancer Inst 1997;89:442-446.

50. Cohn JA, Bornstein JD, Jowell PS. Cystic fibrosis mutations and genetic predisposition to idiopathic chronic pancreatitis. Med Clin North Am 2000;84:621-631.

51. Hamosh A, Fitz-Simmons SC, Macek M, Jr, Knowles MR, Rosenstein BJ, Cutting GR. Comparison of the clinical manifestations of cystic fibrosis in black and white patients. J Pediatr 1998;132: 255-259.

52. Friedman KJ, Heim RA, Knowles MR, Silverman LM. Rapid characterization of the variable length polythymidine tract in the cystic fibrosis (CFTR) gene. Association of the 5T allele with selected CFTR mutations and its incidence in atypical sinopulmonary disease. Hum Mutat 1997;10:108-115.

53. Witt DR, Schaefer C, Hallam P, Wi S, Blumberg B, Fishbach A, Holtzman J, Kornfeld S, Lee R, Nemzer L, Palmer R. Cystic fibrosis heterozygote screening in 5,161 pregnant women. Am J Hum Genet 1996;58:823-835.

54. Gasparini P, Arbustini E, Restagno G, Zelante L, Stanziale P,
Gatta L, Sbaiz L, Sedita AM, Banchieri N, Sapone L, Fiorucci GC, Brinson E, Shulse E, Rappaport E, Fortina P. Analysis of 31 CFTR mutations by polymerase chain reaction/oligonucleotide ligation assay in a pilot screening of 4476 newborns for cystic fibrosis. J Med Screen 1999;6:67-69.

Received May 8, 2001. Accepted August 23, 2001

Address requests for reprints to: Jonathan A. Cohn, M.D., Box 3378,

Duke University Medical Center, Durham, North Carolina 27710. e-mail: cohn0001@mc.duke.edu; fax: (919) 684-4983.

Supported in part by grants from the Department of Veterans Affairs, the Cystic Fibrosis Foundation, and the National Institutes of Health.

Drs. Noone and Zhou contributed equally to this work.

The authors thank R. Pace and C. Foy for technical assistance, S. Minnix for assistance recruiting subjects, Dr. S. Schmidt for assistance with statistics, and the following physicians for providing clinical data about their patients: J. D. Bornstein, J. Baillie, M. S. Branch, and W. R. Treem (Duke University Medical Center), T. Desai (Beaumont Hospital, Royal Oaks, MI), S. Shutz (Wilford Hall Medical Center, Lackland AFB, TX), T. H. Baron (University of Alabama Medical Center, Birmingham, $A L$ ), and N. E. Vinton (Gastroenterology Associates, P.A., Newark, DE). 